Please do not remove this page

RMIT

UNIVERSITY

\title{
Participatory research with an online drug forum: A survey of user characteristics, information sharing, and harm reduction views
}

Chiauzzi, Emil; DasMahapatra, Pronabesh; Lobo, Kimberley; Barratt, Monica

https://researchrepository.rmit.edu.au/esploro/outputs/9921860723001341/filesAndLinks?institution=61RMIT_INST\&index=null

Chiauzzi, E., DasMahapatra, P., Lobo, K., \& Barratt, M. (2013). Participatory research with an online drug forum: A survey of user characteristics, information sharing, and harm reduction views. Substance Use and Misuse, 48(8), 661-670. https://doi.org/10.3109/10826084.2013.800117

Document Version: Accepted Manuscript

Published Version: https://doi.org/10.3109/10826084.2013.800117

Repository homepage: https://researchrepository.rmit.edu.au

CC BY-NC-ND V4.0

Copyright (C) 2013 Informa Healthcare USA, Inc.

Downloaded On 2023/04/26 23:25:20 +1000

Please do not remove this page 
Participatory Research with an Online Drug Forum: A Survey of User Characteristics, Information Sharing, and Harm Reduction Views

\author{
Emil Chiauzzi, Ph.D. ${ }^{1}$ \\ Pronabesh DasMahapatra, MD, $\mathrm{MPH}^{2}$ \\ Kimberly Lobo, M.S., MPH ${ }^{3}$ \\ Monica J. Barratt, Ph.D. ${ }^{4}$
}

${ }^{1}$ Emil Chiauzzi, Ph.D. (Corresponding Author)

Vice President, Research and Innovation

Inflexxion, Inc.

320 Needham Street, Suite 100

Newton, MA 02464

Phone: 617-332-6028, X229

Fax: 617-332-1820

Email: echiauzzi@inflexxion.com

${ }^{2}$ Biostatistician

Inflexxion, Inc.

${ }^{3}$ Epidemiologist

Inflexxion, Inc.

${ }^{4}$ Director of Research @ Bluelight.ru and

Research Fellow

National Drug Research Institute, Curtin University

54-62 Gertrude Street

Fitzroy, Victoria 3065

Australia

Word Count: 3719 


\begin{abstract}
Background: Online communication technologies, including forums or message boards, have become increasingly influential among young adults who use illicit drugs, including the nonmedical use of prescription opioids. There is a lack of empirical information about the characteristics of participants using these websites.

Objectives: To apply a participatory research model for surveying forum users': (1) demographic characteristics; (2) substance use history; (3) forum activity; and (4) harm reduction beliefs.

Methods: Visitors to an online drug forum were invited to complete an online survey. Those who reported current prescription opioid use were asked additional questions about nonmedical use, duration of use, and co-ingestion of other drugs.

Results: Respondents in this survey were primarily Caucasian males in their twenties who were generally not employed full-time and who completed at least some college. Respondents reported a fairly high level of forum involvement and the majority of forum readers share posted information with other drug users. Participants overwhelmingly endorsed harm reduction as a way to minimize drug harms. There were key differences between current nonmedical prescription opioid users and others visiting the site, as the former reported more activity in forums, as well as a greater likelihood of past substance abuse treatment.

Conclusions: The use of a participatory research strategy enhanced survey participation. The visitors to this website may not represent drug users in general, but offer a glimpse into the world of illicit and prescription drug users that is unrepresented in governmental and national drug studies.
\end{abstract}

\title{
Keywords
}

Nonmedical prescription opioid use

Survey

Drug forum

Harm reduction

Participatory research 


\section{Introduction}

Nearly half of American adults use social networking websites, about double the number who used these sites in 2008 (Hampton et al., 2011). Such usage is especially prevalent among young adults (18-29), as 72\% use social networking websites (Pew Internet and American Life Project, 2010). The young adult age cohort evidences the highest rate of illicit drug use (SAMHSA, 2012), so it is not surprising that conversations about drug use have migrated onto the popular Internet drug use forums and message boards (Wax, 2002).

Visitors utilize these websites in a number of ways, e.g., learning about new drugs, sharing methods of using drugs, finding help for friends or family members, and even conducting academic research. Although the nature of these interactions varies greatly, several drug forums promote harm reduction, i.e. the minimization of immediate drug-related harms (Hunt et al., 2003). Harm reduction approaches are pragmatic and non-judgmental, and may or may not focus on treatment goals such as abstinence (Hunt et al., 2003; Marlatt and Witkiewitz, 2010).

There is a wide range of drug users who populate these forums, but many can be characterized as recreational users (Baggott et al., 2010; Nicholson et al., 1999; Stetina et al., 2008; Temple and Brown, 2011). In general, recreational drug users do not consider themselves addicted to drugs, do not see a need for treatment, and are not interested is discontinuing drug use (Stetina et al., 2008). Unfortunately, the current empirical knowledge base about the characteristics and motivations of individuals who frequent online drug forums is limited. Available evidence indicates that drug forums are populated overwhelmingly by males in their twenties (Baggott et al., 2010; Stetina et al., 2008; Temple and Brown, 2011). This pattern holds for forum members who use salvia divinorum (Baggott et al., 2010) and cannabis (Temple and Brown, 2011). Drug forum participants are generally employed or attending college (Stetina et 
al., 2008; Temple and Brown, 2011) and one survey found unremarkable mental health, physical health, and community functioning in this population (Nicholson et al., 1999).

Drug forum members retain a strong interest in substances that they use and may be open to sharing information about their use (Stetina et al., 2008). Researchers, clinicians, and addiction professionals have become increasingly concerned about the role of the Internet in facilitating user access to risky drug use practices, most notably nonmedical ${ }^{1}$ prescription medication use (Nielsen and Barratt, 2009; Cone, 2006; Butler et al., 2007). In keeping with a harm reduction philosophy, some forum users may discuss safety profiles of newly available opioids and ways of using currently available medications more safely. However, others may seek to compare opioid medications in terms of the "high" that can be achieved, get feedback about the optimal routes of administration for particular medications, or learn new tampering methods (Cone, 2006).

In general, recreational drug users are a “hidden” and under-researched population (Stetina et al., 2008; Miller and Sønderlund, 2010), as most drug use studies focus on more salient drug use populations (e.g., clients in drug treatment). Online forums are of particular value when attempting to research stigmatized populations, who may be difficult to recruit through traditional means (Barratt and Lenton, 2010). Online surveys have proven successful in eliciting honest and accurate portrayals of illicit drug use (Duncan et al., 2003; Turner et al., 1998). However, the less visible and more sensitive an activity is, the more difficult it is to achieve representative samples (Faugier and Sargeant, 1997). Although research from online surveys of drug users frequenting drug forums may not be representative of the drug-using population at large, online survey methodology is advantageous because of improved access to

\footnotetext{
${ }^{1}$ Nonmedical use is the use of a medication without a prescription, in a way other than as prescribed, or for the experience or feelings elicited (NIDA, 2011).
} 
difficult to reach groups, ease and speed of data collection, and improved respondent confidentiality (Miller and Sønderlund, 2010).

Researchers who have approached online drug forums to survey sensitive drug topics have encountered a high degree of hostility and suspiciousness by forum members, so rapport building is critical (Temple and Brown, 2011). By moving "beyond recruitment” and engaging online drug users in a participatory research approach, online surveys can become more effective and informative (Barratt and Lenton, 2010). Rather than relying on simple survey posting, participatory research in this setting adopts several innovative research strategies: (1) development of relationships with forum administrators to enhance recruitment and engage participants; (2) communicating with participants during the study to answer questions and respond to comments; (3) gaining familiarity with the online community to understand how the group might react to outside research activities; (4) engagement of participants through all stages of the research process, from recruitment to offering links to findings and publications; and (5) providing public credit to the drug forum as a contributor to the research project (with their permission) (Barratt and Lenton, 2010).

The present study focused on visitors to a popular drug use forum, with a particular focus on nonmedical prescription opioid users. We adopted a participatory research model and collaborated with moderators, surveying forum users': (1) demographic characteristics; (2) substance use and substance abuse treatment history; (3) traffic to, posting in, and the use of information that was accessed in the forum; and (4) beliefs about the key tenets of harm reduction philosophy. By attracting a range of drug forum visitors to the survey, we were able to make comparisons between those who were current nonmedical prescription opioid users and those who were not. 


\section{Methods}

\subsection{Bluelight.ru}

Seven recreational drug use websites on the Internet were considered. The following criteria were applied in the process of choosing a website for the survey: (1) English language; (2) an active and unedited, but moderated, message board; (3) volunteer staffing; and (4) open to research studies. We selected Bluelight.ru, which is a publicly available, international message board that: (1) educates the public about making informed decisions regarding personal drug use, (2) advocates harm reduction to minimize the risks of drug use, and (3) has a public commitment to drug research. Working with Bluelight administrators, we developed survey items and an online "flyer" that was posted as a banner link on the entry page. After the study began, the investigators kept the moderators apprised of survey participation and the Bluelight administrators increased participation reminders as needed. Because online discussion can influence responses to surveys, the investigators requested that forum discussions of the survey be kept to a minimum. Finally, the investigators agreed to post survey results at the end of the study and to provide forum members with information about future publication(s) of the data.

\subsection{Survey design}

The survey included four major sections: demographics, alcohol and other drug use, website participation, and harm reduction beliefs. Participants who did not endorse alcohol or other drug use were branched out from that section of the survey. Demographic variables included age, race, gender, country of residence, education, and employment status. Participants were asked about lifetime, past-year and current (past 30-day) use of alcohol, prescription opioids and illicit drugs ${ }^{2}$, as well as their history with different types of substance abuse

\footnotetext{
2 Illicit drugs include cocaine (or crack), designer drugs (e.g., Ecstasy), hallucinogens (e.g., LSD, mushrooms, PCP), heroin, inhalants (e.g., glue), marijuana, methamphetamine.
} 
treatment Current prescription opioid users were asked about: (1) nonmedical vs. prescribed use; (2) duration of use; and (3) co-ingestion with other drugs. Participants’ activities (posting, viewing discussions) in online recreational drug and other harm reduction websites were evaluated. In addition participants were also asked about their reasons for visiting, posting, use of information, how they determine the validity of information that they view. Respondents also rated (1=“strongly disagree” to 5=“strongly agree”) beliefs pertinent to the harm reduction philosophy.

Completion of the entire survey took about twenty minutes, and was somewhat shorter for those who did not report prescription opioid use. Validity standards were embedded into the survey to identify data from individuals who intentionally wanted to mislead the research or were not taking the survey seriously thereby requiring consistent answers to certain questions. Survey responses were collected using the online data collection software Vovici 6 Enterprise Edition (Vovici Corp., Herndon, VA. 2012), and stored in a secure database. The research protocol was approved by the New England Institutional Review Board (NEIRB). It should be noted that participation in the survey was voluntary, the nature and potential risks of the study were explained, and no identifying information was collected. Participants were not remunerated.

\subsection{Data analyses}

Statistical analysis was carried out in the following steps: (1) data were assessed for normality; (2) descriptive statistics were reported, using frequency and percentage for categorical variables and median and Interquartile range for age; $95 \%$ Confidence Intervals (C.I.) were reported where appropriate; and (3) bivariate comparisons were performed using Wilcoxon ranksum test for age, and chi-square tests for categorical variables. Data analyses were carried out using SAS version 9.3 (SAS Institute, Cary, North Carolina, 2011). The significance 
level was set at $\alpha=.05$.

\section{Results}

\subsection{Sample characteristics}

Individuals from the United States (U.S.) as well as non-U.S. locations (majority from United Kingdom, Australia and Canada) who volunteered to participate in this survey were recruited online between November 2011 and January 2012. One thousand nine hundred and seventy $(\mathrm{N}=1,970)$ individuals viewed the survey description, of which 1,667 individuals consented to participate. A total of 178 individuals were under 18 years of age, and hence ineligible to participate. Furthermore, 38 individuals gave invalid answers and were excluded from the study. Of the remaining 1,451 valid respondents, 897 individuals completed the entire survey and were retained for analyses ${ }^{3}$. The survey abandonment rate was $38 \%$, slightly lower than Internet surveys of similar length (Galesic, 2006). Figure 1 represents the flow of participants through the study.

\section{[Insert Figure 1 here]}

Demographic characteristics of the survey sample $(n=897)$ are presented in Table 1. The median age of the survey sample was 25.3 years (Interquartile range: 21.1 - 32.8). Participants were primarily male (75.8\%) and Caucasian (85.7\%). Most (79.4\%) had attended at least some college or associate program, including 29.0\% who were college graduates, postgraduates, or professionals. In terms of employment status, $40.7 \%$ were employed, $26.8 \%$ were students, and $20.5 \%$ were not employed.

\section{[Insert Table 1 here]}

\footnotetext{
${ }^{3}$ Most participants dropped out after the first few survey questions; 98\% of survey participants who proceeded to alcohol and other drug use questions completed the entire survey.
} 
Most of the study participants resided in the United States (62.5\%), followed by the United Kingdom (11.5\%), Australia (8.8\%) and Canada (5.8\%). We explored differences in participant characteristics by residency status (U.S. versus non-U.S. participants). Of note, differences in age, gender, race, and education status were observed; a greater percentage of non U.S. participants were male (80.7\% versus $72.9 \%$ ), and Caucasian (90.5\% versus $82.9 \%$ ), however, a lower percentage of non-U.S. participants were college graduates or higher as compared to U.S. participants (72.6\% versus 83.4\%). Further, we compared differences in characteristics among respondents who dropped out versus those who completed the surveys. Overall, differences were small between dropouts (71.2\% college graduates or higher) versus completers (79.4\% college graduates or higher).

About a third (34.7\%) of the survey participants reported ever receiving some form of substance abuse treatment. The treatment modalities included outpatient treatment (62.4\%), twelve-step groups (59.5\%), detoxification (50.8\%), inpatient treatment (48.6\%), and residential treatment (25.7\%). More U.S. participants indicated receiving treatment for alcohol and drug problems as compared to their non U.S. counterparts (39.9\% versus $25.9 \%)$.

\subsection{Alcohol and other drug use}

As expected, the prevalence of current (past 30-day) alcohol and other illegal drug use was extremely high in this sample (Table 2); 64.4\% reported current use of alcohol, followed by marijuana (52.3\%), designer drugs (24.2\%), hallucinogens (21.1\%), cocaine (12.1\%), heroin (10.9\%), methamphetamine (8.0\%) and inhalants (3.0\%). Less than half (43.3\%) of the survey participants indicated using prescription opioids by any means (use as prescribed and nonmedical use), the majority of which were nonmedical users (70.9\%). Among nonmedical prescription opioid users, the median number of days of use in the past 30-days was 10.6. The current use of 
opiates (prescription opioids by any means and heroin) was significantly higher among U.S. residents, with $48.5 \%$ and $13.6 \%$ reporting current use of prescription opioids and heroin, respectively. In contrast, among non-U.S. residents, 34.5\% were current prescription opioid users and only 6.6\% current heroin users. However, non-U.S. participants reported higher current use of alcohol (71.1\%) and designer drugs (32.7\%) as compared to U.S participants (60.4\% and 19.1\%, respectively). A minority of the sample $(n=207,23.1 \%)$ did not use any illicit drugs (illegal drugs and prescription opioids nonmedically) in the past 30-days.

We also explored differences in responses between individuals who were current (past 30-day) nonmedical prescription opioid users ( $n=275,30.7 \%)$ and those who did not report nonmedical prescription opioid use in the past 30-days $(n=622,69.3 \%)$. Of note, demographic characteristics of the two groups were comparable. More current nonmedical prescription opioid users reported ever receiving treatment for alcohol and/or drug problems (44.8\% vs. 30.2\%).

\section{[Insert Table 2 here]}

Among current nonmedical prescription opioid users, multidrug co-ingestion was a common occurrence, with $68.4 \%$ reporting the concurrent use of illicit drugs with opioids. Of note, use of prescription opioids nonmedically was most commonly noted to co-occur with marijuana (48.4\%), heroin (18.9\%), cocaine (16.0\%), hallucinogens (13.1\%), designer drugs (12.4\%), methamphetamine (6.9\%) and inhalants (2.6\%).

\subsection{Website participation}

The majority of the participants were registered members of Bluelight.ru (72.9\%); whereas only 3.1\% reported never visiting bluelight.ru forums. The other recreational drug websites frequented by these individuals included Erowid.org (84.4\%), Drugs-Forum.com (59.1\%), Opiophile.org (37.4\%), Hipforums.com (29.6\%), Topix.com (23.5\%), 
Drugsandbooze.com (19.2\%), and Poppies.org (14.3\%). With the exception of Bluglight.ru, Erowid.org was the most visited website for viewing discussions and threads in forums (75.7\%).

Figure 2 depicts the level of participation on bluelight.ru among participants who visit the discussion forums and threads $(\mathrm{n}=869)$. Most participants read discussions/threads $(97.1 \%)$ and posted messages in discussions/threads (65.6\%) at least one or more times a year. In terms of reading discussion and threads within the forums, $26.6 \%$ reported daily access, $41.1 \%$ once a week or more, and $18.5 \%$ about once a month. Similarly, $10.8 \%$ posted in discussion/threads daily, $21.7 \%$ once a week or more, and $13.1 \%$ about once a month. About $35 \%$ did not post at all.

\section{[Insert Figure 2 here]}

\subsection{Recreational drug and harm reduction website activities}

The most common reasons cited for visiting the site were to "learn how to use drugs more safely" and "how to help others use drugs more safely” (77.8\% and 58.2\%, respectively). Forum posts from this group mostly pertained to “questions about illegal drugs” (65.3\%) and “questions about ways of using illegal drugs more safely” (58.5\%). Further, the majority (50.2\%) of forum readers shared information from posts with others who were using illegal drugs or prescription pain medications. Most participants indicated following up information read at Bluelight.ru with their own research (90.6\%), or from people they know (36.1\%) and health professionals (24.5\%). Current nonmedical prescription opioid users were more actively involved in the Bluelight.ru forums than non-current users, especially pertaining to queries about drug use in general (e.g., "Learn how to use drugs more safely”, "Find new ways of using drugs/medications” etc.) and specifically for prescription opioids (e.g., “Questions about prescription pain medications”, “Attempted to extract active ingredients of a prescription pain 
medication”) (see Table 3 for details). Participant activities in the Bluelight.ru forums are presented in Table 3.

\section{[Insert Table 3 here]}

\subsection{Harm reduction}

Participants' levels of agreement with the harm reduction statements included in this survey are illustrated in Figure 3. Of note, most participants endorsed (agreed or strongly agreed) the idea of being responsible for their own drug use behavior (last four statements in Figure 3. e.g., "Drug use is a fact of life and the only realistic approach is to minimize harm”), whereas, fewer participants endorsed the idea of social dynamics as the factor for drug use and abuse (e.g., “Social inequalities are the major cause of drug addiction”). Almost half (45\%) of respondents agreed or strongly agreed with the statement "Alcoholism and drug addiction are diseases."

\section{[Insert Figure 3 here]}

\section{Discussion}

The current survey builds upon previous drug forum research by revealing: (1) the prevalence of use of illicit drugs and prescription opioids among forum members; (2) ways in which forum users traffic Bluelight.ru and communicate drug-related information; and (3) the extent to which forum users believe the common principles of harm reduction. We also found key differences between forum users who were current nonmedical prescription opioid users and others visiting the site, as they reported more activity in Bluelight forums, as well as a greater likelihood of past substance abuse treatment.

This demographic picture of respondents in this survey is similar to participants of past drug forum studies (Baggott et al., 2010; Stetina et al., 2008; Temple and Brown, 2011). Respondents in this survey were primarily Caucasian males in their twenties who were generally 
not employed and who completed at least some college. The rates of current illicit drug use were extremely high, with rates of cocaine, heroin, and marijuana/hashish well above population norms (SAMHSA, 2012). The nonmedical use of prescription opioids in this sample may represent particular cause for concern: (1) almost 75\% of those who used opioids in the past month used them nonmedically; (2) opioid medications were used nonmedically more than 10 days per month; (3) there was significant concurrent use of other substances, especially marijuana, heroin, and cocaine; and (4) almost half of current nonmedical prescription opioid users reported that they had received treatment for alcohol or drug addiction problems in the past. As established in other studies, our findings suggest that nonmedical prescription opioid use is often associated with the use of other illicit substances (e.g., Green et al., 2011; Wu et al., 2010).

Respondents in this survey reported a fairly high level of forum involvement, as $41 \%$ read messages and about $60 \%$ posted messages once a week or more. This is somewhat higher than previous online community studies, which found that more than half of online community visitors are "lurkers" (Nonnecke and Preece, 2000). It should be noted that almost one quarter of respondents were not current drug users, and it is possible that some may have been occasional drug users or visiting the website for informational or research purposes. In fact, there are anecdotal reports that addiction counselors, pharmacists, physicians, researchers and law enforcement officials visit online drug forums to monitor drug use trends (Shaw, 2012).

For many users, visiting Bluelight is not a passive experience. In accordance with Bluelight's harm reduction philosophy, the most common reason that people visit the site is to learn how to use drugs more safely. Within this sample, respondents posted questions about prescription pain medications, how to use these medications more safely, new prescription pain 
medications that became available and extracting active ingredients from medications. The majority of forum readers share posted information with other drug users. A significant number of current illicit drug and nonmedical prescription opioid users reported attempting to extract active ingredients from prescription pain medications after reading it at Bluelight.ru. Nonmedical prescription opioid users were particularly interested in seeking out new ways of using and extracting addictive compounds. However, only a very small proportion of Bluelight.ru users accept posted information at face value. Almost 90\% reported that they followed up with their own research. The picture that emerges from these survey results is one of an inquisitive drug user. This may reflect the college backgrounds of many Bluelight members, past experience with substance abuse treatment, and/or the analytical and research-oriented tone of the forum.

Not surprisingly, respondents in this study overwhelmingly endorsed harm reduction as a realistic solution to drug use problems and minimizing drug harms. Only a minority of respondents viewed societal inequality as a cause of drug problems. Despite moderate support for the disease concept, respondents did not support the notion of abstinence as a requirement for recovery from alcohol or drug addiction. This may partially reflect the popularity of the harm reduction philosophy around the world. Taken together, findings indicate the importance of personal agency and individual needs in reducing drug harms. Individuals who use drugs are more likely to reduce harms if they maintain the power to set their own goals (Ruefli and Rogers, 2004). Indeed, a study of drug users receiving a broad array of services found that the "most preferred way of living was one in which they could try to work things out for themselves and remain independent of the dominant culture” (Ruefli and Rogers, 2004).

Online surveys are often subject to non-representative samples and a self-selection bias (Eysenbach, 2004). As in previous surveys of drug forums, the primary limitation in this study is 
the use of convenience sampling, which may attract more active users of the website. A potential limitation of results obtained from online surveys of this population of drug users is the extent to which these data represent actual practices of those who abuse these drugs (Katz et al., 2008). The difficulties of achieving randomized samples with hidden populations have been welldocumented (Faugier and Sargeant, 1997; Miller and Sønderlund, 2010), and researchers have concluded that there needs to be a balance between methodology and the value of the data to be obtained from the targeted sample. We do not assume this sample is representative of wider populations of drug users, nor can we say this sample is representative of the Bluelight population, but we can add this to growing number of studies of online forum drug user samples, and contribute to available knowledge of this group.

The strengths of this survey are notable. We carefully defined a participatory research approach for data collection and dissemination, which resulted in a high level of participation and information sharing. The survey gauged the experiences and impressions of a relatively small but important group of substance users. These individuals tend to be highly involved in the drug world in terms of polysubstance abuse, the use of prescription opioids, and sharing of drug information. It may be easy for some to dismiss or judge these individuals, who represent an unheard segment of society. However, in the spirit of participatory research and harm reduction, substance abuse professionals have much to learn from drug forum members. Recreational drugrelated websites offer a novel glimpse into the world of illicit and prescription drug users that is unrepresented in governmental and national drug studies. Because the Internet is considered to be a data source that can act as an "early warning” system for drug use (Mounteney and Leirvåg, 2004), further participatory investigations with online populations may yield additional insights that can inform drug policies, secondary and tertiary drug abuse prevention, and treatment. 


\section{Role of Funding Source}

Nothing declared.

\section{Contributors}

Authors Chiauzzi, DasMahapatra, and Lobo designed the survey and wrote the study protocol. Barratt reviewed and provided revisions for the survey. DasMahapatra programmed the online survey and completed the statistical analysis. Chiauzzi, DasMahapatra, and Lobo wrote the first draft of the manuscript, which was reviewed and revised by Barratt. All authors contributed to and approved the final manuscript.

\section{Conflict of Interest}

No conflicts declared.

\section{Acknowledgements}

We would like to thank Bluelight participants for sharing their views and experiences. We also appreciate the collaboration with the two Bluelight.ru forum Owners and Directors, SG and TLB. Finally, we would like to acknowledge the following individuals who provided helpful comments about the manuscript: Stephen Butler, Ph.D.; Traci Green, Ph.D.; Theresa Cassidy, MPH; and Emily McNaughton, MPH. 


\section{References}

Baggott, M.J., Erowid, E., Erowid, F., Galloway, G.P., Mendelson, J., 2010. Use Patterns and Self-Reported Effects of Salvia Divinorum: An Internet-Based Survey. Drug Alcohol Depend. 111(3), 250-6.

Barratt, M.J., Lenton, S., 2010. Beyond Recruitment? Participatory Online Research with People Who Use Drugs. Int J Internet Res Ethics. 3, 69-86.

Butler SF, Venuti SW, Benoit C, Beaulaurier RL, Houle B, Katz N., 2007. Internet Surveillance: Content Analysis and Monitoring of Product-Specific Internet Prescription Opioid AbuseRelated Postings. Clin J Pain. 23(7), 619-28.

Cone, E.J., 2006. Ephemeral Profiles of Prescription Drug and Formulation Tampering: Evolving Pseudoscience on the Internet. Drug Alcohol Depend. 83(Suppl), S31-S39.

Duncan, D.F., White J.B., Nicholson T., 2003. Using Internet-Based Surveys to Reach Hidden Populations: Case of Nonabusive Illicit Drug Users. Am J Health Behav. 27(3), 208-18.

Eysenbach, G., 2004. Improving the Quality of Web Surveys: The Checklist for Reporting Results of Internet E-Surveys (CHERRIES). J Med Internet Res. 6(3), e34. doi: 10.2196/jmir.6.3.e34.

Faugier, J., Sargeant, M., 1997. Sampling Hard to Reach Populations. J Adv Nurs. 26, 790-797. 
Galesic, M., 2006. Dropouts on the Web: Effects of Interest and Burden Experienced During an Online Survey. J Off Stat. 22(2), 313-328.

Green T.C., Black R., Grimes Serrano, J.M., Budman, S,H., Butler, S.F., 2011. Typologies of Prescription Opioid Use in a Large Sample of Adults Assessed for Substance Abuse Treatment. PLoS ONE. 6(11): e27244. doi:10.1371/journal.pone.0027244.

Hampton, K.N., Goulet , L.S., Rainie, L., Purcell, K., 2011. Social Networking Sites and Our Lives. Washington, D.C.: Pew Internet and American Life Project. http://pewinternet.org/ /media//Files/Reports/2011/PIP\%20\%20Social\%20networking\%20sites\%20and\%20our\%20lives.pdf. [Accessed on 10.4.12].

Henning, J., 2009. Skip Logic and Conditional Branches in Surveys. http://blog.vovici.com/blog/bid/18190/Skip-Logic-Conditional-Branches-in-Surveys. [Accessed on 10.5.12].

Hunt, N., Ashton, M., Lenton, S., Mitcheson, L., Nelles, B., Stimson, G., 2003. A Review of the Evidence-Base for Harm Reduction Approaches to Drug Use. London: Forward Thinking on Drugs. http://www.ihra.net/files/2010/05/31/HIVTop50Documents11.pdf. [Accessed on 10.23.12].

Katz, N., Fernandez, K., Chang, A., Benoit, C., and Butler, S.F., 2008. Internet-Based Survey of Nonmedical Prescription Opioid Use in the United States. Clin J Pain. 24(6), 528-535. 
Marlatt, G. A., Witkiewitz, K., 2010. Update on Harm Reduction Policy and Intervention Research. Ann Rev Clin Psychol. 6, 591-606.

Miller, P.G., Sønderlund, A.L., 2010. Using the Internet to Research Hidden Populations of Illicit Drug Users: A Review. Addiction. 105, 1557-1567.

Mounteney, J., Haugland S, 2004. Earlier Warning: A Multi-Indicator Approach to Monitoring Trends in the Illicit Use of Medicines. Int J Drug Policy. 20(2), 161-169.

National Institute on Drug Abuse, 2011. Prescription Drugs: Abuse and Addiction. Research Report Series. Bethesda (MD): National Institute on Drug Abuse. http://www.drugabuse.gov/sites/default/files/rrprescription.pdf. [Accessed on 9.14.12]

Nicholson, T., White, J., Duncan, D. F., 1999. A Survey of Adult Recreational Drug Use Via the World Wide Web: The DRUGNET Study. J Psychoactive Drugs. 31, 415-422.

Nielsen, S., Barratt, M.J., 2009). Prescription Drug Misuse: Is Technology Friend or Foe? Drug Alcohol Rev. 28, 81-6.

Nonnecke, B., Preece, J., 2000. Persistence and Lurkers: A Pilot Study. In Proc. HICSS-33 (Maui, Hawaii), IEEE Computer Society. http://www.cis.uoguelph.ca/ nonnecke/research/persistence.pdf. [Accessed on 10.23.12]. 
Pew Internet and American Life Project. (2010). Social Media and Young Adults. http://pewinternet.org/ /media//Files/Reports/2010/PIP_Social_Media_and_Young_Adults_Rep ort_Final_with_toplines.pdf. [Accessed on 10.4.12].

Ruefli, T., Rogers, S.J., 2004. How Do Drug Users Define Their Progress in Harm Reduction Programs? Qualitative research to develop user-generated outcomes. Harm Reduct J. 1:8 doi:10.1186/1477-7517-1-8.

SAS Institute Inc., 2011. SAS ${ }^{\circledR} 9.3$ System Options: Reference ( $2^{\text {nd }}$ ed.). Cary, NC: SAS Institute Inc.

Shaw, G., 2012. Painkiller Abuse for Dummies: Opioid Misuse Gets Online “How To” Treatment. Pain Med News. 10(4).

http://www.painmedicinenews.com/ViewArticle.aspx?d=Science\%2B\%26\%2BTechnologyandd _id=354andi=April+2012andi_id=826anda_id=20581. [Accessed on 9.10.12].

Stetina, B. U., Jagsch, R., Schramel, C., Maman, T. L., Kryspin-Exner, I., 2008). Exploring Hidden Populations: Recreational Drug Users. Cyberpsychology: J Psychosocial Res Cyberspace. 2(1) http://cyberpsychology.eu/view.php?cisloclanku=2008060201andarticle=1 [Accessed on 9.18.12].

Substance Abuse and Mental Health Services Administration. (2012). Results from the 2011 National Survey on Drug Use and Health: Summary of National Findings, NSDUH Series H-44, 
HHS Publication No. (SMA) 12-4713. Rockville, MD: Substance Abuse and Mental Health Services Administration.

http://www.samhsa.gov/data/NSDUH/2k11Results/NSDUHresults2011.pdf. [Accessed on 9.17.12].

Temple, E.C., Brown, R.F., 2011. Research Design: A Comparison of Internet-Based Participant Recruitment Methods: Engaging the Hidden Population of Cannabis Users in Research. J Res Pract. 7(2), Article D2. http://jrp.icaap.org/index.php/jrp/article/view/288/247. [Accessed on 9.13.12].

Turner, C.F., Ku, L., Rogers, S.M., Lindberg, L.D., Pleck, J.H., Sonenstein, F.L., 1998. Adolescent Sexual Behavior, Drug Use, and Violence: Increased Reporting with Computer Survey Technology. Science. 280, 867-873.

Vovici Corporation, 2012. Vovici 6. Herndon, VA: Vovici Corporation.

Wax, P.M., 2002. Just a Click Away: Recreational Drug Web Sites on the Internet. Pediatrics, 109(6), e96.

Wu, L.T., Woody, G.E., Yang, C., Blazer, D.G., 2010. Subtypes of Nonmedical Opioid Users: Results from the National Epidemiologic Survey on Alcohol and Related Conditions. Drug Alcohol Depend. 112, 69-80. 


\section{Tables}

\section{Table 1. Demographic characteristics of the study sample ${ }^{a}$}

\begin{tabular}{|c|c|c|c|c|}
\hline & Total Sample & US residents & $\begin{array}{l}\text { Non US } \\
\text { residents }\end{array}$ & $p$-value ${ }^{b}$ \\
\hline $\mathrm{N}$ & 897 & 561 & 336 & \\
\hline Age (years) & $25.3(11.7)$ & $25.5(13.3)$ & $25.2(11.0)$ & 0.05 \\
\hline Gender & & & & 0.03 \\
\hline Male & 75.8 & 72.9 & 80.7 & \\
\hline Female & 23.8 & 26.6 & 19.0 & \\
\hline Prefer not to respond & 0.4 & 0.5 & 0.3 & \\
\hline Race & & & & 0.02 \\
\hline White & 85.7 & 82.9 & 90.5 & \\
\hline African American & 1.0 & 1.6 & 0.0 & \\
\hline Hispanic/Latino origin & 2.7 & 3.4 & 1.5 & \\
\hline Asian & 2.3 & 2.9 & 1.5 & \\
\hline American Indian/Alaskan Native & 0.8 & 1.2 & 0.0 & \\
\hline Pacific Islander/Native Hawaiian & 0.2 & 0.2 & 0.3 & \\
\hline Mixed & 4.6 & 5.2 & 3.6 & \\
\hline Other & 2.7 & 2.7 & 2.7 & \\
\hline Education & & & & $<0.001$ \\
\hline Less than high school & 5.0 & 3.2 & 8.0 & \\
\hline High school graduate & 15.6 & 13.4 & 19.4 & \\
\hline Some College/Associate degree & 50.4 & 56.7 & 39.9 & \\
\hline College graduate/Post Graduate/Professional & 29.0 & 26.7 & 32.7 & \\
\hline Employment & & & & 0.58 \\
\hline Full-time & 31.2 & 30.8 & 31.8 & \\
\hline Part-time & 9.5 & 9.8 & 8.9 & \\
\hline Not employed & 20.5 & 21.8 & 18.5 & \\
\hline Retired & 1.9 & 2.1 & 1.5 & \\
\hline Student & 26.8 & 24.8 & 30.1 & \\
\hline Military & 0.8 & 0.7 & 0.9 & \\
\hline Other & 9.3 & 10.0 & 8.3 & \\
\hline Alcohol and Drug Treatment & 34.7 & 39.9 & 25.9 & $<0.001$ \\
\hline
\end{tabular}

\footnotetext{
${ }^{a}$ Data expressed as percentage, except age shown as Median (Interquartile range)

${ }^{\mathrm{b}} \mathrm{P}$-value for comparison between US and non US residents calculated by performing chi-square tests for categorical variables and Wilcoxon rank-sum test for age, no adjustments were made for multiple comparisons.
} 
Participatory Research with an Online Drug Forum 23

Table 2. Prevalence of current (past 30-day) substance use in the study sample ${ }^{a}$

\begin{tabular}{|c|c|c|c|c|c|c|c|c|c|}
\hline \multirow[b]{2}{*}{$\mathrm{N}$} & \multicolumn{3}{|c|}{ Total Sample } & \multicolumn{3}{|c|}{ US residents } & \multicolumn{3}{|c|}{ Non US residents } \\
\hline & \multicolumn{3}{|c|}{897} & \multicolumn{3}{|c|}{561} & \multicolumn{3}{|c|}{336} \\
\hline & \multirow[t]{2}{*}{$\%$} & \multicolumn{2}{|c|}{ 95\% C.I. } & \multirow[t]{2}{*}{$\%$} & \multicolumn{2}{|c|}{ 95\% C.I. } & \multirow[t]{2}{*}{$\%$} & \multicolumn{2}{|c|}{ 95\% C.I. } \\
\hline & & LCL & UCL & & LCL & UCL & & LCL & UCL \\
\hline \multicolumn{10}{|l|}{ Prescription Opioid } \\
\hline Any use $* * *$ & 43.3 & 40.0 & 46.5 & 48.5 & 44.3 & 52.7 & 34.5 & 29.5 & 39.8 \\
\hline Nonmedical use $* * *$ & 30.7 & 27.7 & 33.7 & 35.3 & 31.4 & 39.3 & 22.9 & 18.5 & 27.8 \\
\hline Alcohol ** & 64.4 & 61.2 & 67.6 & 60.4 & 56.3 & 64.5 & 71.1 & 66.0 & 75.9 \\
\hline Cocaine & 12.1 & 10.1 & 14.5 & 12.8 & 10.2 & 15.9 & 11.0 & 7.9 & 14.9 \\
\hline Designer Drugs $* * *$ & 24.2 & 21.4 & 27.1 & 19.1 & 15.9 & 22.6 & 32.7 & 27.7 & 38.0 \\
\hline Hallucinogens & 21.1 & 18.4 & 23.9 & 20.0 & 16.7 & 23.5 & 22.9 & 18.5 & 27.8 \\
\hline Heroin ** & 10.9 & 9.0 & 13.1 & 13.6 & 10.8 & 16.7 & 6.6 & 4.2 & 9.8 \\
\hline Inhalants & 3.0 & 2.0 & 4.4 & 3.7 & 2.3 & 5.7 & 1.8 & 0.6 & 3.9 \\
\hline Marijuana & 52.3 & 49.0 & 55.6 & 52.6 & 48.4 & 56.8 & 51.8 & 46.3 & 57.2 \\
\hline Methamphetamine & 8.0 & 6.3 & 10.0 & 7.1 & 5.1 & 9.6 & 9.5 & 6.6 & 13.2 \\
\hline
\end{tabular}

Note: Bold font indicates significant differences $(\mathrm{p}<0.05)$ between US and non-US residents.

${ }^{\mathrm{a}}$ Data expressed as percentage

Illicit drugs include cocaine (or crack), designer drugs (e.g., Ecstasy), hallucinogens (e.g., LSD, mushrooms, PCP), heroin, inhalants (e.g., glue), marijuana, methamphetamine.

${ }^{*} \mathrm{p}<0.05,{ }^{* *} \mathrm{p}<0.01, * * * \mathrm{p}<0.001$ 
Participatory Research with an Online Drug Forum 24

Table 3. Participant activities in Bluelight.ru forums

\begin{tabular}{|c|c|c|c|}
\hline Reasons for visiting (\%) & $\begin{array}{c}\text { All } \\
\text { participants }\end{array}$ & $\begin{array}{c}\text { Current } \\
\text { nonmedical } \\
\text { Rx opioid } \\
\text { users }\end{array}$ & $\begin{array}{c}\text { Other } \\
\text { Illicit drug } \\
\text { users and } \\
\text { nonusers }\end{array}$ \\
\hline $\mathrm{N}$ & 897 & 275 & 622 \\
\hline To be a part of the community ** & 48.2 & 56.0 & 44.7 \\
\hline Learn how to use drugs more safely $* *$ & 77.8 & 84.0 & 75.1 \\
\hline Learn how to help others use drugs more safely $* *$ & 58.2 & 64.7 & 55.3 \\
\hline Find new drugs/medications to use & 40.0 & 44.0 & 38.3 \\
\hline Find new ways of using drugs/medications $* * *$ & 44.3 & 54.6 & 39.7 \\
\hline Learn about drug use trends & 46.5 & 49.8 & 45.0 \\
\hline Conduct academic research $* *$ & 19.2 & 24.7 & 16.7 \\
\hline Never visited Bluelight forum & 3.1 & 1.5 & 3.9 \\
\hline Other & 14.6 & 13.1 & 15.3 \\
\hline
\end{tabular}

Type of information posted ${ }^{a}$

Questions about illegal drugs

Questions about prescription pain medications ***

Ways of using illegal drugs more safely

Ways of using prescription pain medications more safely ***

Ways of extracting active ingredients from prescription pain medications $* * *$

New illegal drugs that have become available

New prescription pain medications that have become available ***

Getting help for a personal drug problem **

Getting help for someone else with a drug problem

Questions about drug laws/police regulations

Other

\section{3}

41.7

58.5

40.3

23.1

28.3

16.3

31.1

20.6

28.9

22.0
62.7

69.2

57.3

66.0

39.5

31.9

25.4

39.5

20.0

30.8

18.4

23.9

What was done based on reading information posted ${ }^{\mathrm{b}}$

Sought out a new illegal drug for recreational use

25.3

22.9

26.4

Used an illegal drug in a new way

30.5

34.0

28.9 
Participatory Research with an Online Drug Forum 25

Obtained a new prescription pain medication for recreational use ***

Obtained a new prescription pain medication to treat a valid medical problem $* * *$

$\begin{array}{lll}10.5 & 18.5 & 6.9 \\ 13.6 & 22.9 & 9.4 \\ 22.8 & 38.8 & 15.6 \\ 35.4 & 41.3 & 32.8 \\ 24.2 & 42.8 & 15.7 \\ 50.2 & & \\ 7.5 & 57.6 & 46.8 \\ 22.6 & 14.4 & 26.3\end{array}$

Attempted to extract active ingredients of a prescription pain medication $* * *$

Tried an illegal drug use method that someone said was safer *

Tried a prescription pain medication use method that someone said was safer $* * *$

Shared information with someone who was using illegal drugs or prescription pain medications **

Note, categories are not mutually exclusive and hence percentages may sum to greater than $100 \%$. Data expressed as percentage

${ }^{a}$ Type of information posted on bluelight.ru asked only to those subjects who were registered members of bluelight and post in forums $(\mathrm{n}=570)$

${ }^{b}$ What was done based on reading information posted on bluelight.ru asked only to those subjects who visit the bluelight.ru forums $(\mathrm{n}=869)$

$* \mathrm{p}<0.05, * * \mathrm{p}<0.01, * * * \mathrm{p}<0.001$ 


\section{Figures}

\section{Figure 1. Survey response rate}

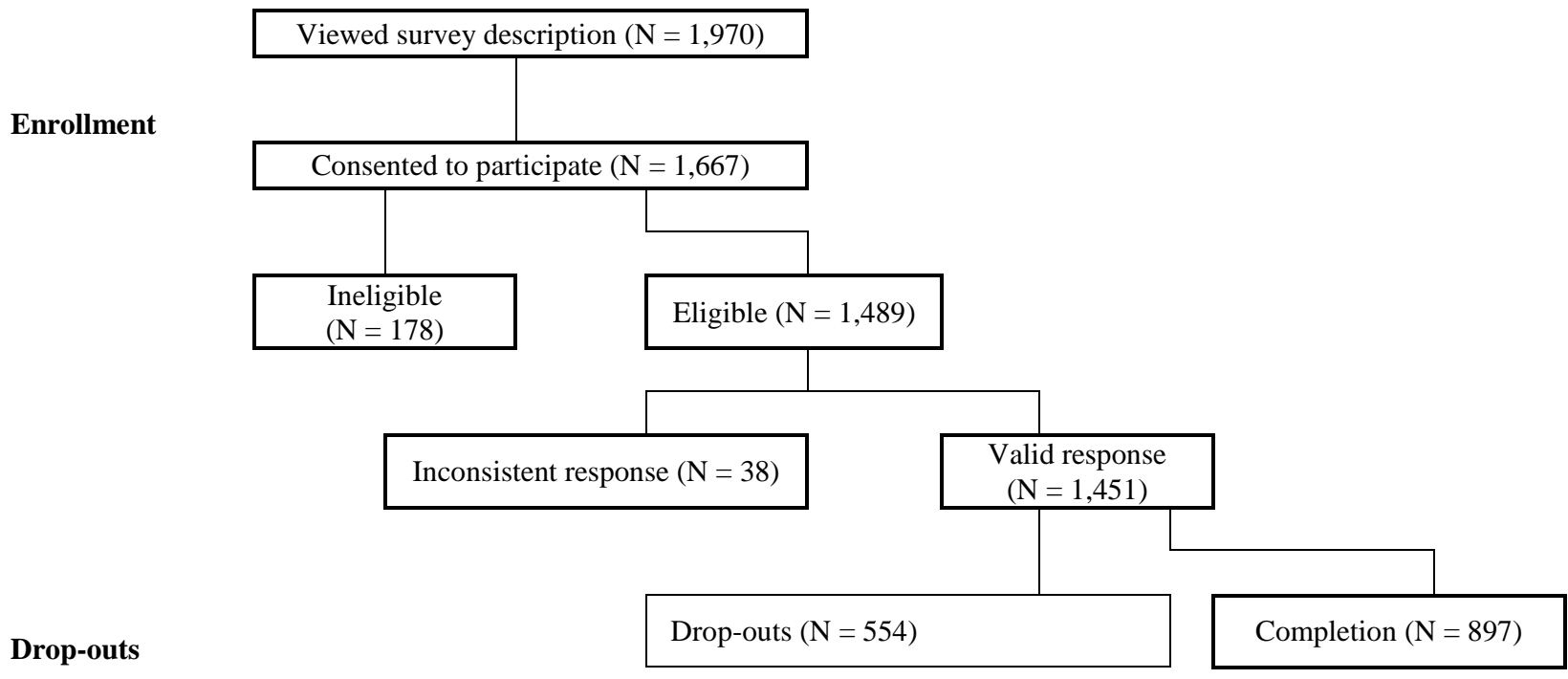


Figure 2. Level of involvement on Bluelight.ru

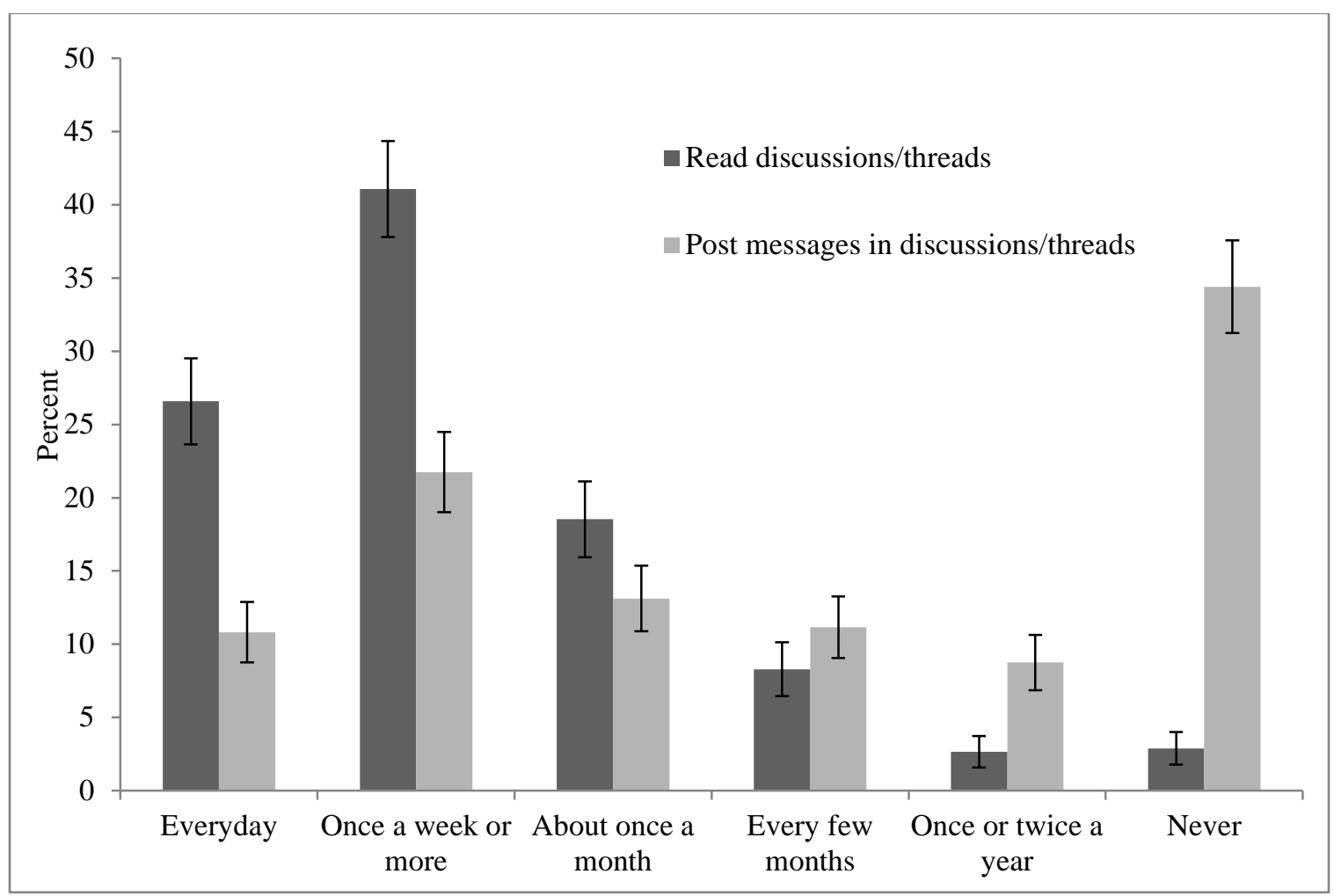

Note: level of involvement in Bluelight forum calculated for only those subjects who visit the Bluelight.ru forums $(n=869)$ 


\section{Figure 3. Harm reduction views ${ }^{a}$}

Abstinence is required for recovery from alcohol and/or drug addiction

Alcoholism and drug addiction are diseases

Social inequalities are the major cause of drug addiction

Marijuana should be legalized

When people are in recovery from addiction, quality of life is more important than abstinence

Drug use is OK as long as you don't hurt anybody else

Drug users themselves are the primary agents of reducing the harms of their drug use

Drugs don't have to be dangerous - you have to know how to use them

Drug use is a fact of life and the only realistic approach is to minimize harm

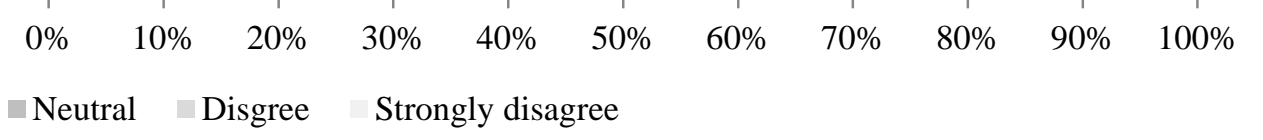

$\square$ Strongly agree $\square$ Agree $\square$ Neutral $\square$ Disgree $\quad$ Strongly disagree

Data expressed as percentage

${ }^{\text {a }}$ Rate your level of agreement with the following statement 